\title{
Optimum three-point linkage set up for improving the quality of soil spectra and the accuracy of soil phosphorus measured using an on-line visible and near infrared sensor
}

A. M. Mouazen ${ }^{\text {a }}$, M. R. Maleki ${ }^{\text {b, c }}$, L. Cockx ${ }^{\mathrm{d}}$, M. Van Meirvenne ${ }^{\mathrm{d}}$, L. H. J. Van Holm ${ }^{\mathrm{e}}$, R. Merckx $^{\text {e }}$, J. De Baerdemaeker ${ }^{\text {b }}$, H. Ramon ${ }^{b}$

${ }^{a}$ Natural Resources Department, Cranfield University, MK43 OAL, United Kingdom, e-mail: a.mouazen@cranfield.ac.uk, Tel.: +44 1234 750111, Fax: +44 1234752971

${ }^{b}$ Division of Mechatronics, Biostatistics and Sensors (MeBioS), Department of Biosystems, Faculty of Bioscience Engineering, Kasteelpark Arenberg 30, B-3001 Heverlee, Belgium

${ }^{c}$ Department of Agricultural Machinery, College of Agriculture, Shahid Bahonar University of Kerman, P.O. Box 76169-133, Kerman, Iran

${ }^{d}$ Research Group Soil Spatial Inventory Techniques, Department of Soil Management and Soil Care, Ghent University, Coupure 653, 9000 Gent, Belgium

${ }^{e}$ Division of Soil and Water Management, Laboratory of Soil and Water Management, Faculty of Bioscience Engineering, Kasteelpark Arenberg 20, B-3001 Heverlee, Belgium

\section{Abstract}

On-line measurement of soil properties using the visible (Vis) and near infrared (NIR) spectroscopy is sensitive to soil-to-sensor distance (D) and angle $(\alpha)$ variations, which have prevented the successful development of on-line soil sensors so far. This study was undertaken to minimise these variations through optimising the three-point linkage of the tractor to improve the quality of soil spectra and the accuracy of plant available phosphorus (P-avl) measured with an on-line soil sensor. The sensor consisted of a tine, to the back of which an optical probe was attached to acquire soil spectra in diffusive reflectance mode from the bottom of the trench opened by the tine. A mobile, fibre-type, Vis-NIR spectrophotometer (Zeiss Corona 45 visnir fibre, Germany), with a measurement range of $306.5-1710.9 \mathrm{~nm}$ was used. Five lengths of the third point link (L) of the tractor of 545, 550, 555, 560 and $565 \mathrm{~mm}$ were selected to evaluate the quality of spectra collected on-line at $0.15 \mathrm{~m}$ tine depth. The on-line measured spectra were corrected to remove the effect of $\mathrm{D}$ and $\alpha$. The correction was evaluated by estimating the 
accuracy of predicting P-avl using on-line measured spectra and a previously developed P-avl

34

35 calibration model.

Results showed that the best quality of spectra measured on-line was obtained for L of 555 $\mathrm{mm}$, at which $\mathrm{D}$ and $\alpha$ vanished. This finding was supported by the maximum value of average maximum reflectance (AMR) of $75.7 \%$ obtained and by $100 \%$ successfully collected spectra. The worst quality of spectra was obtained at L of $545 \mathrm{~mm}$, with the largest D of $6 \mathrm{~mm}$ and the largest $\alpha$ of $0.6^{\circ}$. Values of $\mathrm{L}$ of 560 and $565 \mathrm{~mm}$ led to a decrease in the AMR (43.3 and $33.2 \%$, respectively), while recording $100 \%$ successful spectra. Correction of on-line measured spectra led to clear improvements in the accuracy of on-line measured P-avl. A lower root mean

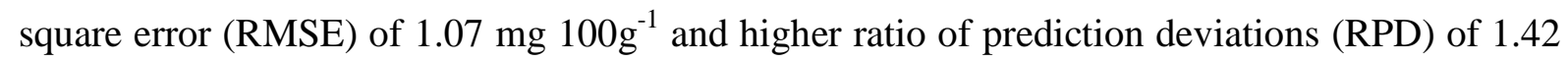
were obtained with corrected spectra as compared to uncorrected spectra (RMSE $=1.15$ and $\mathrm{RPD}=1.39$ ). In addition, the correction of spectra resulted in an increase in the degree of similarity between laboratory and on-line measured P-avl maps by $29.6 \%$. These results suggest the need for optimising the tractor hydraulic three-point linkage set up, and for spectra correction in order to improve the accuracy of on-line measured soil properties.

Keywords: visible; near infrared; spectrophotometer; on-line, soil sensor.

\section{Introduction}

Visible (Vis) and near infrared (NIR) diffusive reflectance spectroscopy is a promising measurement technique available to provide rapid information about soil physical and chemical properties, e.g. moisture, carbon, nitrogen, phosphorus and calcium content; and cation 
56 exchange capacity in an economical manner (Ben-Dor and Banin, 1995; Chang et al., 2001;

57 Reeves and McCarty 2001; Odlare et al., 2005; Cozzolino and Morón, 2006; Maleki et al.,

58 2006a; Wetterlind et al., 2008). When light is illuminated towards the soil surface, the radiant energy is distributed through three different processes: reflection, absorbance and transmission (Dahm and Dahm, 2001). Since transmission for opaque materials such as soils equals zero, the balance between reflection and absorbance is governed by the influence of soil physical and chemical properties (Mouazen et al., 2005). The Vis-NIR spectroscopy was adopted by many research groups to measure soil properties. Although several researchers reported off-line nonmobile measurement of soil properties, only few studies on on-line measurement of soil properties were reported (Shonk et al., 1991; Sudduth and Hummel, 1993; Shibusawa et al., 2003; Mouazen et al., 2005). This is attributed to difficulties in designing a sensor that can penetrate the soil and acquire spectra successfully (Mouazen et al., 2007). In addition, lower accuracy associated with providing general calibration models valid over a wide geographical area enhances limiting the attraction of researchers to develop a working on-line sensor. However, research is required to improve the performance of the few on-line Vis-NIR sensors exist, since on-line data acquisition about soil is useful input for sensor-based variable rate application of different inputs into agricultural soils (Maleki et al., 2007).

Based on laboratory measurement of soil spectra using a Vis-NIR spectrophotometer, we found the diffusive light reflected from the soil surface decreases with the increasing soil-tosensor distance (D) and angle between the soil and sensor ( $\alpha$ ). These two parameters induce undesired changes in spectra, which requires a correction algorithm to retain the original spectral features. Other researchers encountered the same problem during the development of 
79 2003). Generally, D affects the accuracy of prediction of soil properties e.g. carbon, nitrogen,

80 etc (Sudduth and Hummel, 1993). Mouazen et al. (2005) claimed that they were able to

81 minimise D variation by introducing reasonably similar maps of moisture content developed by

82 an on-line sensor and oven drying method. In fact, the highest light reflection from the soil

83 surface can be recorded when direct contact between the soil and the sensor $(\mathrm{D}=0 \mathrm{~mm}$ and $\alpha=$

$840^{\circ}$ ) is ensured. During on-line measurement of soil properties the direct contact should be

85 fulfilled, bearing in mind that vibration can always exist during measurement that might disturb

86 the collection of spectra. However, the vibration induced noise can be eliminated from the

87 spectra by spectra pre-processing such as smoothening, normalisation and/or multiplicative

88 scatter correction (Mouazen et al., 2005).

89 In order to keep the sensor in continuous contact with the soil, two conditions have to be

90 taken into consideration. Firstly, a proper mechanical design of the optical probe (the unit that

91 penetrates the soil and collects soil spectra) has to be provided, which should ensure continuous

92 penetration of the soil, preparation of a smooth soil surface and preservation of direct contact

93 between the soil and the optical probe (Mouazen et al., 2005; Mouazen et al., 2007). The other

94 condition is to ensure a proper calibration of the tractor three-point linkage, in order to attain

95 transactional and longitudinal levelling of the optical probe. This has to be accompanied with

96 manual adjustment of the tractor hydraulic system to locate the sensor to the required depth,

97 while preserving levelling of the sensor.

98 The main objective of this study was to develop a methodology to optimise the tractor three-

99 point linkage system set up, aiming at minimising D and $\alpha$ and improving the quality of on-line

100 collected soil spectra. The second aim of this study was to evaluate the effect of correction of 
101

102

103

104

105

106

107

108

109

110

111

112

113

114

115

116

117

118

119

120

121

122

123

on-line measured spectra on the accuracy of prediction of plant available phosphorus in soil (Pavl).

\section{Materials and methods}

\subsection{Portable, fibre-type visible and near infrared spectrophotometer}

\section{7}

The spectrophotometer was a fibre-type Vis-NIR instrument developed by Zeiss Company (Zeiss Corona 45 visnir fibre, Germany). It is fast ( 1 soil scan per $0.4 \mathrm{sec}$ ) and of small size, has no moving parts, and has been successfully used on mobile machines e.g. to measure grain quality on combines (Reyns et al., 2001; Maertens et al., 2004), soil moisture content (Mouazen et al., 2005) and extractable $\mathrm{P}, \mathrm{P}-\mathrm{avl}$, total carbon, organic carbon and $\mathrm{pH}$ (Mouazen et al., 2007). It was also used to optimise an on-line variable rate applicator of triple super phosphate $\left(\mathrm{P}_{2} \mathrm{O}_{5}\right)$ during maize planting based on on-line measurement of soil extractable phosphorus using the on-line Vis-NIR sensor of this study, shown in Fig. 1 (Maleki et al., 2006b; Maleki et al., 2007). The instrument has, in addition to the Si-array available for the measurement in the Vis and short infrared wavelength region $(306.5$ - $1135.5 \mathrm{~nm})$, an InGaAs diode-array for the measurement in the NIR region $(944.5-1710.9 \mathrm{~nm})$. The light source is a 20 Watt tungsten halogen lamp illuminating the targeted soil surface with a spot of 2-3 mm light through an optic fibre. The illumination and reflectance fibres were positioned at a $45^{\circ}$ angle in an optical probe used to carry out reflectance measurement from the soil surface prepared by the tine (Fig. 2). Standard white (75\% reflectance) and black (7\% reflectance) references were used. 


\subsection{On-line visible and near infrared soil sensor}

The on-line measurement system consisted of a penetration tine (subsoiler), to which the optical probe is attached (Fig. 1). The tine and optical probe were set on a frame, which was mounted onto the three-point linkage of the tractor. It is a simple frame, which has a metal wheel on each side to regulate the subsoiler depth. However, depth control is only done in the downwards direction by the two wheels. The upwards movement of the tine due to tractor driving over a higher spot than that of the sensor driven behind can not be controlled. The depth (draught based) control system linked to the hydraulic system of the tractor had to be set at minimum response to draught variation during the field test to reduce vibration and variation in $\mathrm{D}$ and $\alpha$. The tine penetrates the soil to any required depth between 5 and $40 \mathrm{~cm}$, making a trench, whose bottom is smoothened due to the downwards force acting on the tine. This downwards force increases friction between the flat bottom of the tine and its retrofitted probe with the soil, which improves smoothening of the bottom of the trench and maximises light reflectance.

\subsection{Laboratory calibration of the measurement system}

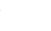

A preliminary test was undertaken under laboratory conditions to set the three-point linkage and the hydraulic system of the tractor in a proper position that would ensure the tine penetration to a depth of $15 \mathrm{~cm}$, while preserving the optical probe in a horizontal position (angle $\alpha$ and D $=0$ in Fig. 2a) parallel to the bottom of the trench opened by the subsoiler. The horizontal probe levelling included longitudinal and transactional adjustments of the upper third 
147 point link and lower two-point links, respectively. The experiment showed that the optimal L is $148555 \mathrm{~mm}$, for which a longitudinal (parallel to the direction of travel) levelling of the optical 149 probe was achieved. In order to insure this position of the optical probe, the hydraulic system of 150 the tractor was manually adjusted to a given level. This optimal calibration set up obtained

\subsection{Field measurement}

\subsubsection{Evaluation of the effect of different third point link lengths on quality of spectra}

To verify the laboratory calibration of the three-point linkage hydraulic system, on-line measurement of soil spectra was carried out on a Haplic Luvisol (FAO classification) field in Heverlee, $30 \mathrm{~km}$ east of Brussels (Belgium). The field soil texture determined by wet sieving and a hydrometer test was a silt loam (Table 1), according to the United Stated Department of Agriculture (USDA) system of texture classification. The experiment was carried out in the autumn of 2005 after harvesting sugar beet. The field was even, particularly the plot where the test was carried out. The optical sensor was pulled through 5 parallel lines, $5 \mathrm{~m}$ apart along a 15 $\mathrm{m}$ distance parallel with the direction of the tramlines. Carrying out the measurement within a relatively small area of the field minimised the effect of variable soil conditions and field topography, which allowed information about the effect of $\mathrm{L}$ on the quality of spectra to be extracted. 


\section{Soil and Tillage Research, Volume 103, Issue 1, April 2009, Pages 144-152}

The system was driven at a travel speed of $1.5-2.0 \mathrm{~km} \mathrm{~h}^{-1}$, setting the tine tip at a depth of $0.15 \mathrm{~m}$. Each collected spectrum was an average of 5 successive spectra collected along a distance of $1-1.50 \mathrm{~m}$, depending on tractor speed. The averaged gravimetric moisture content (d.b.) for all lines was at the field capacity (Table 2), ranging between 18.7 and $20.1 \mathrm{~kg} \mathrm{~kg}^{-1}$. Five different $\mathrm{L}$ of $545,550,555,560$ and $565 \mathrm{~mm}$ were adopted. Each length was used for measurement of one individual line. After measurement of an individual line, $\mathrm{L}$ was changed for the next measurement line. This variation in L provided different positions of the optical probe as shown in Fig. 2. Since the variation of $\alpha$ and D are very small (scale of few degrees and millimetres for $\alpha$ and $\mathrm{D}$, respectively), it was not possible to measure them precisely during online measurement. Therefore, they were calculated theoretically under laboratory conditions and reported in Table 2.

\subsubsection{Correction of on-line collected soil spectra}

Due to a technical issue associated with the Vis-NIR spectrophotometer from Zeiss company used in this study, spectral shifts towards the upper or the lower directions were recorded during on-line measurement with most of measured spectra at all L (Fig. 3). The shift occurred at 970 $\mathrm{nm}$, which might be attributed to vibration and/or different $\mathrm{D}$ and $\alpha$ between the background (reference) measurement and soil measurement. Furthermore, this spectral shift could also be due to a differential response between the two detectors used (400-969 nm and 970-1700 nm). A simple test under non-mobile laboratory conditions confirmed that vibration has no effect on the creation of this shift. In fact, vibration induced noise in spectra along the entire wavelength range. Examining the effect of different $D$ and $\alpha$ between white reference measurement $(D=0$ 
192

193

194

195

196

197

198

199

200

207

208

209

210

211

212

$\mathrm{mm}$ and $\alpha=0^{\circ}$ ) and real soil measurement ( $\mathrm{D}>0 \mathrm{~mm}$ and $\alpha \neq 0^{\circ}$ ) proved that the presence of shift in spectra is due to variable D and $\alpha$. The size of this shift depends on the magnitude of $\mathrm{D}$ and $\alpha$.

Spectra correction was done by developing a custom built software using the LabView programming language. This software was based on the assumption of shifting the lower spectra segment (at $306-968 \mathrm{~nm}$ or $972-1700 \mathrm{~nm}$ ) to match the higher part. This was done as follows:

1. The difference in reflectance in $\%$ between 968 and $972 \mathrm{~nm}$ wavelengths was calculated.

2. If the reflectance at wavelength $968 \mathrm{~nm}$ was higher than that at $972 \mathrm{~nm}$, the reflectance difference was added to all wavelengths in the range of $972-1700 \mathrm{~nm}$. While, if the reflectance at wavelength $968 \mathrm{~nm}$ was lower than that at $972 \mathrm{~nm}$, the reflectance difference was added to all wavelengths in the range of $306-968 \mathrm{~nm}$.

2.4.3. Evaluation of the effect of soil-to-sensor distance and angle variations on the prediction accuracy of plant available phosphorus in soil

Previous on-line measurement data from 2004 was recalled to test the effect of spectra correction on improving the accuracy of prediction of P-avl, as an example. Availability of chemical and spectral data from the previous year (2004) allowed the correction approach proposed during Heverlee field measurement in 2005 (see section 2.4.2.) to be tested. The measurement in Heverlee field in 2005 concerned about mechanical calibration only, where no chemical data were available. The correction approach will be tested by comparing the prediction accuracy of $\mathrm{P}-\mathrm{avl}$ before and after removing the shift in spectra. 


\section{Soil and Tillage Research, Volume 103, Issue 1, April 2009, Pages 144-152}

The experimental field in 2004 was a Haplic Luvisol (FAO classification) grass field of 2 ha area and was situated in Lovenjoel near Leuven, and had silt loam texture according to the USDA soil classification (Table 1). The field had a slight slope and was free of tram lines. The field was divided into a 6 by $10 \mathrm{~m}$ grid, as shown in Fig. 4 . The optical sensor was pulled along the longest directions of the field through 18 parallel lines each $6 \mathrm{~m}$ apart at a forward speed of 2-3 $\mathrm{km} \mathrm{h}^{-1}$, setting the tip at a $0.15 \mathrm{~m}$ depth. A total of 126 soil samples were collected mostly from the 6 middle lines (Fig. 4) after sensor passed. Each sample was collected at the bottom of the trench opened by the tine over a distance of $1-1.5 \mathrm{~m}$. The samples were dried and sieved with a $2 \mathrm{~mm}$ sieve, before P-avl was measured using the Olsen method (Olsen et al., 1954). A sufficient amount of wet samples was used to estimate the moisture content by drying in an oven at $105^{\circ}$ for $24 \mathrm{~h}$. The average field moisture content was at the field capacity. The results of soil moisture content and P-avl of these samples are presented in Tables 2 and 3, respectively. A digital global positioning system, Trimble ${ }^{\circledR}$ AgDGPS 132 was used to locate the position of soil spectra. The 126 on-line collected spectra with a location matching the location of the 126 soil samples collected for laboratory analysis of P-avl were later separated from the data set and used to predict $\mathrm{P}$-avl using the model described in a previous study (Maleki et al., 2006a). This model was established using the Partial Least Squares (PLS) analysis with a full cross validation technique on 204 independent spectra of fresh soil samples collected from many fields in Belgium having these texture classes of loamy sand, sandy loam and silt loam. Measurement of spectra used for developing P-avl model was done under laboratory non-mobile measurement conditions. The results of the calibration model and the prediction of P-avl of 126 off-line recorded spectra under laboratory condition of soil samples collected in Lovenjoel field is illustrated in Table 4 (Maleki et al., 2006a). This model was used in this study to predict P-avl 
238 using spectra collected on-line in Lovenjoel field. Maps of laboratory Olsen measured and on239 line predicted P-avl using on-line recorded spectra were developed using geostatistical software 240 (GSLIB). The algorithm used was ordinary kriging (Goovaerts, 1997), which requires the

241

242

243

244

245

246

247

248

249

250

251

252

253

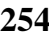

255

256

257

258

259

\section{9}

determination of a variogram model. The experimental variogram was obtained through:

43

$$
\gamma(\mathbf{h})=\frac{1}{2 N(\mathbf{h})} \sum_{\alpha=1}^{N(\mathbf{h})}\left\{z\left(\mathbf{x}_{\alpha}+\mathbf{h}\right)-z\left(\mathbf{x}_{\alpha}\right)\right\}^{2}
$$

where $\gamma(\mathbf{h})$ is the variogram for a distance vector (lag) $\mathbf{h}$ between observations $z\left(\mathbf{x}_{\alpha}\right)$ and $z\left(\mathbf{x}_{\alpha}+\right.$ h), and $N(\mathbf{h})$ is the number of pairs separated by $\mathbf{h}$. The experimental variogram data were modelled by considering the indicative goodness of fit provided by Variowin (Pannatier, 1996). In all cases a spherical model was found to be best:

$$
\begin{aligned}
& \gamma(h)=C_{0}+C_{1} \cdot\left(\frac{3 h}{2 a}-\frac{1}{2}\left(\frac{h}{a}\right)^{3}\right) \quad \text { if } 0<h \leq a \\
& \gamma(h)=C_{0}+C_{1} \quad \text { if } \quad h>a
\end{aligned}
$$

where $C_{0}$ is the nugget effect (Y-intercept), $C_{0}+C_{1}$ is the sill and $a$ is the range. The interpolated map cell size was $1 \mathrm{~m}^{2}$ with 200 rows and 80 columns.

To compare variogram models, they were standardised by: $\gamma(h) /\left(C_{0}+C_{1}\right)$. In this way all variograms received a sill of one.

\section{Results and discussion}




\section{Soil and Tillage Research, Volume 103, Issue 1, April 2009, Pages 144-152}

\subsection{Evaluation of soil spectra collected on-line at different third point link length}

Figure 3 shows soil spectra collected on-line for 5 different experimental lines carried out with 5 different L, reflecting 5 values of angle $\alpha$ and D (Table 2). A total of 8 spectra for each measurement line collected along $15 \mathrm{~m}$ travel distance are shown in Fig. 3.

With L equals to $545 \mathrm{~mm}$ (line A), the quality of spectra is extremely bad. Apart from 8 spectra only one spectrum is a soil spectrum. However, two other spectra are successfully measured by the first detector $(306-945 \mathrm{~nm})$, while no reflection features are captured in the near infrared region of $(946-1700 \mathrm{~nm})$. This poor quality of spectra is attributed to the fact that the sensor focal point falls above the soil surface due to the large D. In this case the incidence of the path of illuminated light and the path of reflected light does not occur at the bottom of trench soil. But, in order to have a maximum collection of electromagnetic energy from the soil surface, the focal point should fall directly on the soil surface, at which D and $\alpha$ vanish. This means that the incidence of the illuminated and reflected light should strictly occur on the soil surface following the passage of the tine and optical probe coming closely behind. The shift in spectra between the two detectors increases in size with increasing D and $\alpha$, until no signal is collected at the NIR range, similar to Fig. 3a. This case can be represented by the position of the measurement system illustrated in Fig. 2b, where the tine inclines towards the forward direction forming an angle $\alpha$ with the horizontal. In this case, D and $\alpha$ are too large (Table 2), for which only a very small amount of diffuse reflected light from the trench bottom could be captured by the probe and reached the detector. Capturing this small amount of light takes place only when the path of illumination light partially met with the path of the reflected light on the soil of the bottom of the trench. 
To evaluate the successful capturing of the reflected light, the maximum reflectance (in percentage) measured for each spectrum was considered. The average maximum reflectance of $7.8 \%$ is found during the measurement through line A. This also proves that a very small percentage of reflected light from the soil surface could be captured.

Increasing L to $550 \mathrm{~mm}$ (line B) decreases D and $\alpha$ (Table 2), and subsequently the quality of collected soil spectra improved (Fig. 3b). This is reflected by the number of successfully collected soil spectra and by the AMR (Table 5). However, the values of these two indicators are still too small to declare a well-levelled position of the optical probe on the bottom of the opened trench. This means that $\alpha$ and D during line B measurement are still relatively big (Table 2), and the probe position is still similar to the case illustrated in Fig. 2 b.

The best soil spectra are collected with L of $555 \mathrm{~mm}$ (Line C in Fig. 3c). This observation is justified by the fact that AMR obtained for line $\mathrm{C}$ is the highest among the 5 experimental setups (Table 5). This case can be illustrated by Fig. 2a, where the tine is at the optimal position allowing the bottom of the optical probe to be in continuous contact with the trench bottom opened by the penetration tine ( $\alpha$ and $\mathrm{D}=0$ ). This position should result in a smoother soil surface at the bottom of the opened trench, and thus maximum light is reflected. The maximum reflection is attributed to the incidence of the illumination light and reflected light on the soil surface prepared by the system (Fig. 2a). The maximum value of AMR obtained here indicates that the signal-to-noise ratio is high, and is higher than the other 5 experimental lines. The percentage of successfully measured spectra is $100 \%$, and all measured spectra can be used for predictions of soil chemical and physical properties. 
With further increase in L to 560 (line D) and $565 \mathrm{~mm}$ (Line E), the quality of soil spectra

(6) acquired degrades. In this case the incidence of the illuminated light and reflected light falls below the reflection surface of the soil (Fig. 2c) leading to light collection from only the edge of the illuminated soil spot. This is reflected by the decrease in AMR values for both lines (Table 5). However, the number of successfully collected spectra does not change (100\% successful spectra). The decrease in the AMR for these two lines would mean a decrease of the signal-tonoise ratio, and eventually the prediction accuracy of soil properties might be influenced. Comparing the spectra collected for each measurement line, it can be concluded that the best quality of spectra is obtained with $555 \mathrm{~mm} \mathrm{~L}$ (zero values of $\mathrm{D}$ and $\alpha$ ), as illustrated in Fig. 3.

\subsection{Correction of on-line measured spectra}

Although L of $555 \mathrm{~mm}$ was found to be the optimal length, at which D and $\alpha$ theoretically vanish, shift still occurs at a wavelength of $970 \mathrm{~nm}$ for most measured spectra, which emphasises the need for spectra correction at any selected L. The disturbed and hollowed soil structure that resulted after sugar beet extraction in Heverlee field could introduce significant variation in $\mathrm{D}$ and $\alpha$, which would explain this shift (Fig. 3). However, in grass or after harvest of cereal crops, the authors found less occurrence of this shift in spectra. In fact, variation in D and $\alpha$ can only be minimised, but not be avoided. The correction of soil spectra adopted in this study to eliminate this shift results in smooth spectra without a shift up or down. Figure 5 shows corrected spectra of those measured at L of $555 \mathrm{~mm}$ (Fig. 3c). These spectra had to be subjected to further pre-processing (normalisation, derivation, smoothing, etc) before it can be used for the 


\section{Soil and Tillage Research, Volume 103, Issue 1, April 2009, Pages 144-152}

327

final prediction of soil properties. The type of spectra pre-processing depends on the type of element to be quantified (Mouazen et al., 2006).

In order to evaluate the usefulness of the correction made on spectra to remove the shift that occurred at 969 - $970 \mathrm{~nm}$ wavelength, the on-line measured spectra (126 spectra) in Lovenjoel field were used to predict P-avl using spectra with and without shift (corrected spectra). The predicted P-avl values of 126 spectra were compared with the corresponding laboratory reference measurement of soil samples collected from the same locations. There is a difference in the prediction accuracy of P-avl values between on-line measured soil spectra collected from field without spectra correction (root mean square error $(\mathrm{RMSE})=1.15 \mathrm{mg} 100 \mathrm{~g}^{-1}$ and ratio of prediction deviations $(\mathrm{RPD})=1.39)$ compared to those predicted with corrected spectra $(\mathrm{RMSE}$

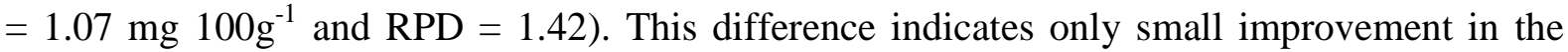
prediction accuracy obtained after correction of spectra, as shown in Table 6. These point-bypoint statistics however do not take the spatial structure of the data into account. Therefore, standardised variograms were calculated and modelled by a spherical model of the 126 laboratory measurements, the uncorrected and the corrected P-avl values (Fig. 6). It can clearly be observed that the variogram of the corrected P-avl approaches more the variogram of the laboratory values compared to the uncorrected values, with both the nugget effect and the range closer to the values of the variogram of the laboratory data. This indicates that the spatial structure of P-avl is better captured by the corrected predictions compared to the uncorrected.

The improvement of using corrected spectra to predict P-avl can also be shown as a map basis. By visually comparing Figs. $7 \mathrm{a}, 7 \mathrm{~b}$ and $7 \mathrm{c}$, similarities in the spatial patterns of $\mathrm{P}$-avl are obvious. Similarity between categorical maps is usually quantified through a statistical kappa (к) value (Cohen, 1960), expressing proportionally how much better the results are compared to 


\section{Soil and Tillage Research, Volume 103, Issue 1, April 2009, Pages 144-152}

a purely random classification. The larger $\kappa$, the more accurate the classification. To obtain categorical maps of P-avl, all maps were classified into five classes based on the 0.2, 0.4, 0.6 and 0.8 quantiles of the interpolated laboratory measurements. The resulting maps are shown in Fig. $8 \mathrm{a}, 8 \mathrm{~b}$ and $8 \mathrm{c}$. The $\kappa$ value of comparing the laboratory classification with the uncorrected $\mathrm{P}$-avl is 0.428 , whereas for the comparison with the corrected P-avl classification $\kappa$ is 0.555 . According to Landis and Koch (1977), the strength of agreement between the laboratory classification and both the classification of the corrected and the uncorrected P-avl was considered to be moderate. Nevertheless, the improvement of using corrected spectra for P-avl prediction results in an increase in map similarity of $29.6 \%$ (based on the $\kappa$ values).

The accuracy of P-avl map developed in this study is much improved compared to that introduced by Mouazen et al. (2007). This improvement can be attributed to the more accurate model used in this study (Maleki et al., 2006a) compared to that used by Mouazen et al. (2007). The model of Maleki et al. (2006a) was built for only three soil textures, namely, loamy sand, sandy loam and silt loam, whereas the model of Mouazen et al. (2007) was built for all texture classes encountered in Flanders, the Northern part of Belgium. Furthermore, the model of Maleki et al. (2006a) used more samples (204) for a smaller number of texture classes (3) as compared to the smaller number of samples (175 samples) for a larger number of texture classes used for the model of Mouazen et al. (2007). This makes the model developed by Maleki et al. (2006a) more accurate than that developed by Mouazen et al. (2007) for prediction of P-avl for these three texture classes. Since the texture of the Lovenjoel field (silt loam) is one of the three textures valid for Maleki et al., (2006a) model, it is logical that more accurate prediction has to be achieved using this model (compared to the that of Mouazen et al. (2007). 
372 Comparing results given in Table 4 with those of Table 6, one can conclude that the accuracy of on-line measurement of P-avl (a smaller $\mathrm{R}^{2}$ of 0.62 , almost equal RMSE of 1.07 and a smaller RPD of 1.42) is rather less than the off-line, non-mobile measurement (a larger $\mathrm{R}^{2}$ of 0.68, almost equal RMSE of 1.08 and a higher RPD of 1.76). The reason of such degradation in the accuracy of P-avl prediction during on-line measurement is the deviation between the starting point of a spectrum measurement as compared to that of corresponding soil sample collected for laboratory chemical analysis. With the most accurate digital global positioning system, a deviation in position of $0.5-1 \mathrm{~m}$ is expected. This deviation might introduce a source of error, since the variability in soil is even smaller than this tolerance (1-0.5 m). Another reason that might introduce a source of error is the larger surface $(1.25 \mathrm{~m})$ scanned by the spectrophotometer compared to the amount of soil considered for the chemical analysis.

\section{Conclusions}

An approach to calibrate the tractor hydraulic system for successful on-line measurement of soil spectra using visible and near infrared spectroscopy was introduced and tested. The calibration included the determination of the optimal length of the tractor third point link (L) and the manual adjustment of the hydraulic system to position the sensor at a specified depth, while preserving a horizontal levelling of the sensor for maximum light reflection detection from the bottom of the opened trench.

For successful on-line measurement, the soil-to-sensor distance (D) and angle ( $\alpha$ ) should be minimised so that maximum electromagnetic energy reflected from the soil surface can be collected. This also requires a successful mechanical design of the on-line sensor that ensures 
395

396

397

398

399

400

401

402

403

404

405

406

407

408

409

410

411

412

413

continuous penetration into the soil, when it is set to the required depth after the proper calibration of the tractor three-point linkage and hydraulic system is achieved. However, each measurement depth requires a different calibration, which has to be carried out separately.

Modifying and correction of soil spectra is essential to improve the accuracy of on-line measured soil properties. This becomes a critical step when on-line measurement is to be carried out after root crops harvest (sugar beet or potato), since the soil layer penetrated by the sensor is disturbed or even contains hollowed space. Therefore, the effect of correction of spectra would have been greater if the crop had been a root crop instead of grass, since smaller variation in D and $\alpha$ is experienced after grain crop harvest.

\section{Acknowledgements}

The authors acknowledge the IWT-Flanders (project nr: IWT/20711) for the financial support.

\section{References}

Ben-Dor, E., Banin, A., 1995. Near-infrared analysis as a rapid method to simultaneously evaluate several soil properties. Soil Sci. Soc. Am. J., 59, 367-372.

Chang, C-W., Laird, D.A., Mausbach, M.J., Hurburgh, C.R., 2001. Near-infrared reflectance spectroscopy-principal component regression analyses of soil properties. Soil Sci. Soc. Am. J., 65(2), 480-490. 
417 Cohen, J., 1960. A coefficient of agreement for nominal scales. Educ. Psychol. Measurement. $418 \quad 20(1), 37-46$.

419 Cozzolino, D., Morón, A. 2006. Potential of near-infrared reflectance spectroscopy and chemometrics to predict soil organic carbon fractions, Soil Tillage Res., 85(1-2), 78-85.

K. (Eds.), Near-Infrared Technology in the Agriculture and Food Industries. American Association of Cereal Chemists, Inc. St. Paul, Minnesota, USA, pp. 1-17

Goovaerts, P., 1997. Geostatistics for Natural Resources Evaluation. Oxford University Press, New York.

Landis, J.R., Koch, G.G., 1977. The measurement of observer agreement for categorical data. Biometrics, 33, 159-174.

Maleki, M.R., Van Holm, L., Ramon, H., Merckx, R., De Baerdemaeker, J., Mouazen, A.M., 2006a. Phosphorus sensing for fresh soils using visible and near infrared spectroscopy. Biosystems Engineering, 95(3), 425-436.

Maleki, M.R., Mouazen, A.M., Ramon, H., De Baerdemaeker, J., 2006b. Optimisation of soil VIS-NIR sensor-based variable rate application system of soil phosphorus. Soil Tillage Res., 94(1), 239-250.

Maleki, M.R., Mouazen, A.M., De Keterlaere, B., Ramon, H., De Baerdemaeker, J., 2007. Onthe-go variable rate phosphorus fertilisation based on a visible and near-infrared soil sensor. Biosystems Engineering, 99(1), 35-46.

Maertens, K., Reyns, P., De Baerdemaeker, J., 2004. On-line measurement of grain quality with NIR technology. Transactions of the ASAE,47(4), $1135-1140$ 
Mouazen, A.M., De Baerdemaeker, J., Ramon, H., 2005. Towards development of on-line soil moisture content sensor using a fibre-type NIR spectrophotometer. Soil Tillage Res., 80(12), 171-183.

Mouazen, A.M., De Baerdemaeker, J., Ramon, H., 2006. Effect of wavelength range on the measurement accuracy of some selected soil properties using visual-near infrared spectroscopy. Journal of Near Infrared Spectroscopy, 14(3), 189-199.

Mouazen, A.M., Maleki, M.R., De Baerdemaeker, J., Ramon, H., 2007. On-line measurement of some selected soil properties using a VIS-NIR sensor. Soil Tillage Res., 93(1), 13-27.

Olsen, S.R., Cole, V.V., Watanabe, F.S., Dean, L.A., 1954. Estimation of available phosphorus in soils by extraction with sodium bicarbonate. U.S. Department. of Agricultural Circular, 939, Washington, DC.

Odlare, M., Svensson, K., Pell, M., 2005. Near infrared reflectance spectroscopy for assessment of spatial soil variation in an agricultural field. Geoderma, 126(3-4), 193-202.

Pannatier, Y. 1996. Variowin. Springer, New York.

Reeves, J.B., McCarty, G.W., 2001. The potential of near infrared reflectance spectroscopy as a tool for spatial mapping of soil composition for use in precision agriculture. Journal of Near Infrared Spectroscopy, 9(1), 25-34.

Reyns, P., Maertens, K., De Baerdemaeker J., 2001. On-line measurement of corn moisture content on a combine harvester using NIR technology. In: Grenier, G., Blackmore, S., (Eds.), Proceedings of the 3rd European Conference on Precision Agriculture. Agro Montpellier, Montpellier, France pp. 851-856.

Shibusawa, S., I made Anom, S.W., Hache, C., Sasao, A., Hirako, S., 2003. Site-specific crop response to temporal trend of soil variability determined by the real-time soil 
473

474

475

476

477

478

479

480

481

482

483

484

485

spectrofotometer. In: Stafford J.V. (Ed), Proceedings of the Joint European Conference of ECPA-ECPLF, Wageningen Academic Publishers, Berlin, Germany, pp. 639-643.

Shonk, J.L., Gaultney, L.D., Schultze, D.G., Van Scoyoc, G.E. 1991. Spectroscopic sensing of soil organic matter content. Transactions of the ASAE, 34(5), 1978-1984.

Sudduth, K.A., Hummel, J.W., 1993. Soil organic matter, CEC, and moisture sensing with a prototype NIR spectrophotometer. Transactions of the ASAE, 36(6), 1571-1582.

Wetterlind, J., Stenberg, B., Jonsson, A., 2008. Near infrared reflectance spectroscopy compared with soil clay and organic matter content for estimating within-field variation in $\mathrm{N}$ uptake in cereals. Plant and Soil, 302(1-2), 317-327.

2

3

4

5

76

7

78

\section{9}


486

487

488

Tables

489

490 Table 1.

491 Soil texture fraction of the experimental field topsoil $(0-20 \mathrm{~cm})$ according to the USDA Soil

492 texture classification

493

\begin{tabular}{lll}
\hline Particle size & Heverlee field & Lovenjoel field \\
\hline & silt loam & silt loam \\
Sand $(>50 \mu \mathrm{m})\left(\mathrm{g} \mathrm{kg}^{-1}\right)$ & 90 & 202 \\
Silt $(2-50 \mu \mathrm{m})\left(\mathrm{g} \mathrm{kg}^{-1}\right)$ & 778 & 697 \\
Clay $(<2 \mu \mathrm{m})\left(\mathrm{g} \mathrm{kg}^{-1}\right)$ & 132 & 101 \\
\hline
\end{tabular}

494

495

496

497

498

499

500

501

502

503

504

505 
Table 2

510 Soil moisture content measured at $15 \mathrm{~cm}$ depth and calculated soil-to-sensor distance and angle

$511 \alpha$ in both experimental fields

\begin{tabular}{|c|c|c|c|c|}
\hline & $\begin{array}{l}\text { Third point link } \\
\text { length }(\mathrm{L}) \\
(\mathrm{mm})\end{array}$ & $\begin{array}{l}\text { Soil-to-sensor } \\
\text { distance }(\mathrm{D}) \\
(\mathrm{mm})\end{array}$ & $\begin{array}{l}\text { Soil-to-angle } \\
\text { angle }(\alpha) \\
\text { (deg) }\end{array}$ & $\begin{array}{l}\text { Average soil } \\
\text { moisture content } \\
\left(\mathrm{kg} \mathrm{kg}^{-1}\right)\end{array}$ \\
\hline \multicolumn{5}{|l|}{ Heverlee field } \\
\hline Line A & 545 & 6 & 0.6 & 20.1 \\
\hline Line B & 550 & 3 & 0.3 & 19.4 \\
\hline Line $C$ & 555 & 0.0 & 0.0 & 19.2 \\
\hline Line D & 560 & 0.0 & -0.2 & 18.7 \\
\hline Line $\mathrm{E}$ & 565 & 0.0 & -0.6 & 19.4 \\
\hline \multicolumn{5}{|l|}{ Lovenjoel field } \\
\hline All field lines & 562 & 0.0 & -0.42 & 16.1 \\
\hline
\end{tabular}

512 
Soil and Tillage Research, Volume 103, Issue 1, April 2009, Pages 144-152

517

518

519

520

521

522 Table 3.

523

524

Chemical analysis results of plant available phosphorus (Olson method) in soil for 126 samples

525 of Lovenjoel field

526

No. Maximum Minimum Mean Standard

(mg 100g $\mathrm{g}^{-1}$ )

$126 \quad 11.0$

2.9

4.8

1.7

527

528

529

530

531

532

533

534

535

536

537

538

539

540 
Table 4.

544 Statistics results of Partial Least Squares (PLS) model of plant available phosphorus in soil (P-

545 avl) resulted from samples collected from many fields of Belgium having texture classes of

546 loamy sand, sandy loam and silt loam (Maleki et al., 2006a)

547

\begin{tabular}{cccc}
\hline Statistics & Calibration & Full cross validation & $\begin{array}{c}\text { Laboratory validation } \\
\text { on off-line spectra }\end{array}$ \\
\hline $\mathrm{R}^{2}$ & 0.83 & 0.73 & 0.68 \\
Slope & 0.83 & 0.76 & 1.007 \\
Offset & 1.219 & 1.71 & -0.709 \\
RMSE (mg 100g $\left.{ }^{-1}\right)$ & 0.943 & 1.202 & 1.08 \\
Bias (mg 100g $\left.{ }^{-1}\right)$ & $-6.3 \times 10^{-7}$ & 0.01157 & 0.67 \\
RPD & - & 1.92 & 1.76 \\
RER & - & 7.22 & 7.72 \\
\hline
\end{tabular}

RMSE, root mean square error

$\mathrm{R}^{2}$, coefficient of determination

550

RPD, ratio of prediction deviations

551

$\mathrm{RER}$, ratio error range

552

553

554

555

556 
559 Table 5.

560 Statistics about on-line collected soil spectra (8 spectra) in Heverlee field at different length of

561 the tractor third point link (L)

562

\begin{tabular}{llccc}
\hline & Length of third & Number of successful & Percentage of & Average \\
& point link (L) & spectra & successful & maximum \\
Line & $(\mathbf{m m})$ & spectra & reflectance (AMR) \\
& & & $(\%)$ & $(\%)$ \\
\hline A & 545 & 1 & 12.5 & 7.79 \\
B & 550 & 4 & 50.0 & 30.60 \\
C & 555 & 8 & 100.0 & 75.68 \\
D & 560 & 8 & 100.0 & 43.28 \\
E & 565 & 8 & 100.0 & 33.15 \\
\hline
\end{tabular}

563

564

565

566

567

568

569

570

571

572 
Table 6.

Statistics results of plant available phosphorus in soil (P-avl) prediction using on-line measured spectra in Lovenjoel field

578

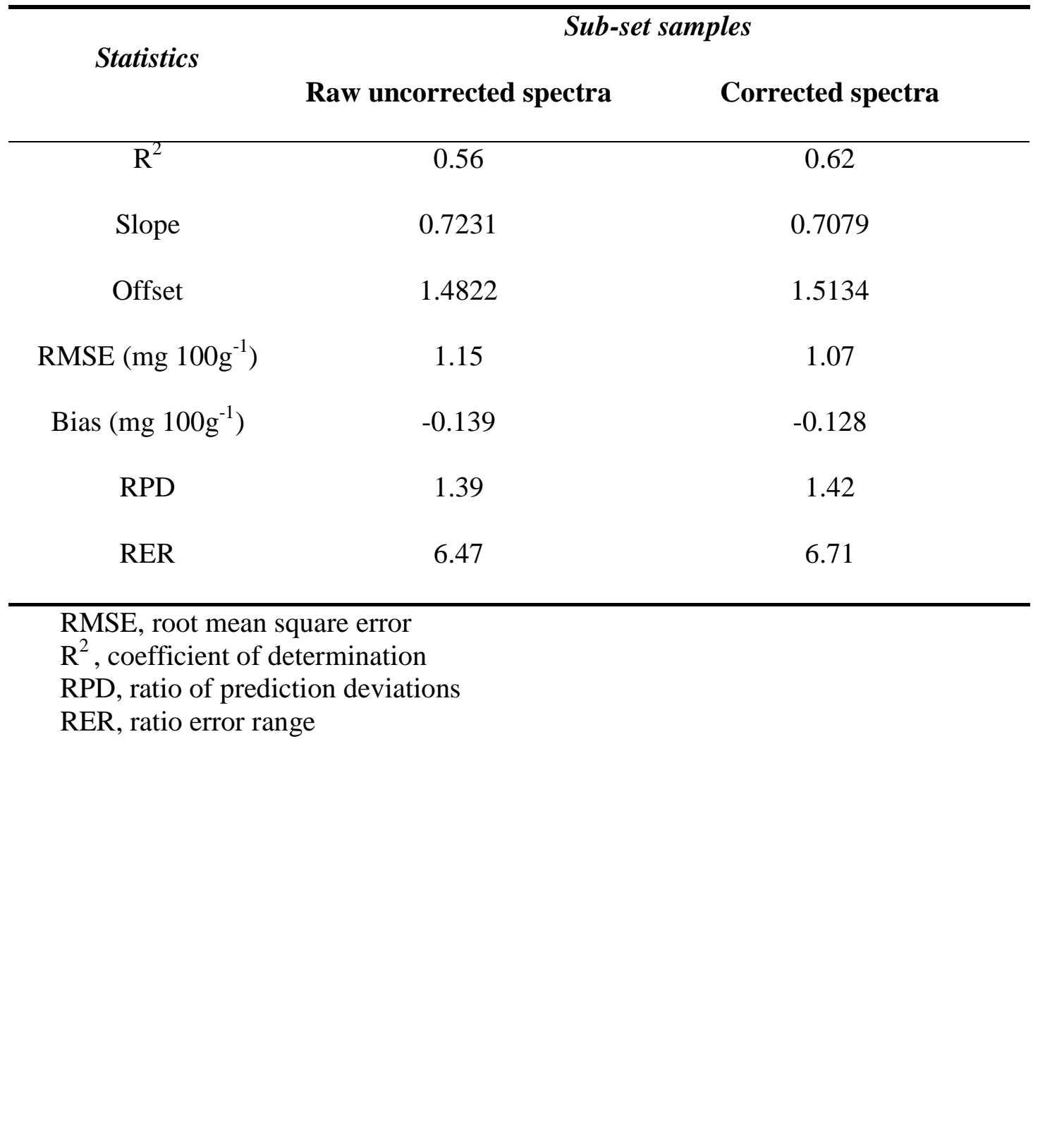

590 
Figure captions

594

595

596

597

598

599

600

601

602

603

604

605

606

607

608

609

610

611

612

613

614

615

616

617

618

619

620

621
Fig. 1. The optical probe attached to the backside of the penetration tine

Fig. 2. Optical path throughout the optical probe for (a) tine at optimal position (b) tine inclined backward (c) tine inclined forward

Fig.3. Recorded soil spectra at different probe inclination angle $(\alpha)$ resulted from different lengths of the tractor third-point link (L); (a) $\alpha=0.6^{\circ}$ at $\mathrm{L}=545 \mathrm{~mm}$; (b) $\alpha=0.3^{\circ}$ at $\mathrm{L}=550$ $\mathrm{mm}$; (c) $\alpha=0.0^{\circ}$ at $\mathrm{L}=555 \mathrm{~mm}$; (d) $\alpha=-0.2^{\circ}$ at $\mathrm{L}=558 \mathrm{~mm}$; (e) $\alpha=-0.6^{\circ}$ at $\mathrm{L}=565 \mathrm{~mm}$

Fig. 4. Soil sampling locations in a grid of 6 by $10 \mathrm{~m}$ in a 100 by $200 \mathrm{~m}$ Lovenjoel field

Fig. 5. Corrected spectra measured for line $\mathrm{C}$ in Heverlee field with $555 \mathrm{~mm}$ long third point link (L)

Fig. 6. Standardised variograms of plant available phosphorus in soil (P-avl) based on laboratory chemical analysis, uncorrected and corrected on-line measured soil spectra in Lovenjoel field

Fig. 7. A 1 by $1 \mathrm{~m}$ grid obtained by ordinary kriging of plant available phosphorus in soil (Pavl) based on: (a) laboratory chemical analysis, (b) uncorrected, and (c) corrected on-line measured soil spectra in Lovenjoel field

Fig. 8. Categorical maps of plant available phosphorus in soil (P-avl) based on (a) laboratory chemical analysis, (b) uncorrected, and (c) corrected on-line measured soil spectra in Lovenjoel field 
Driving direction

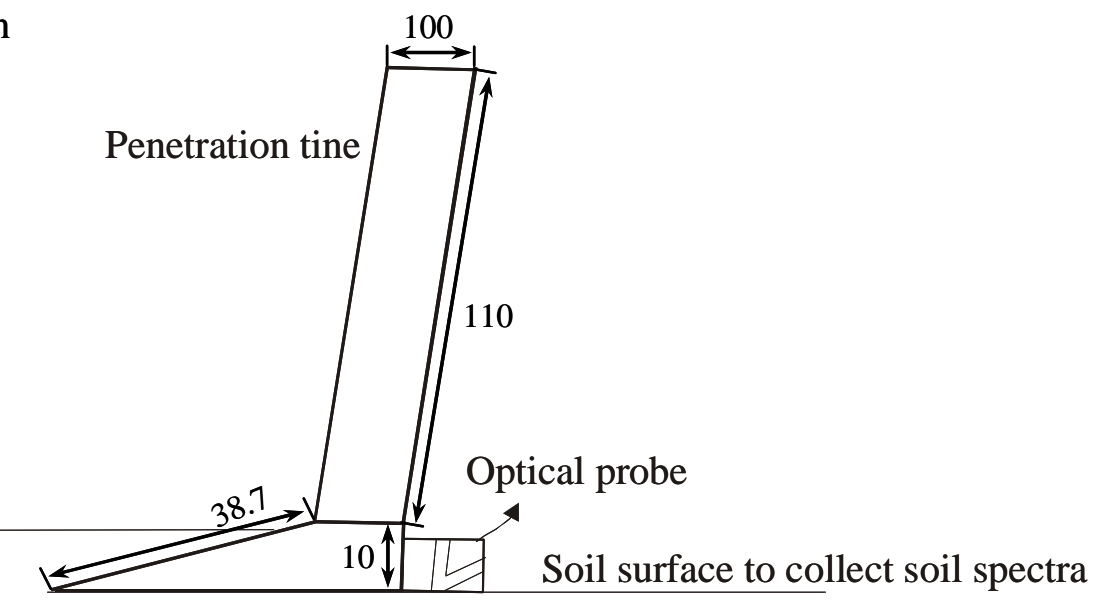

Fig. 1. The optical probe attached to the backside of the penetration tine 
Soil and Tillage Research, Volume 103, Issue 1, April 2009, Pages 144-152

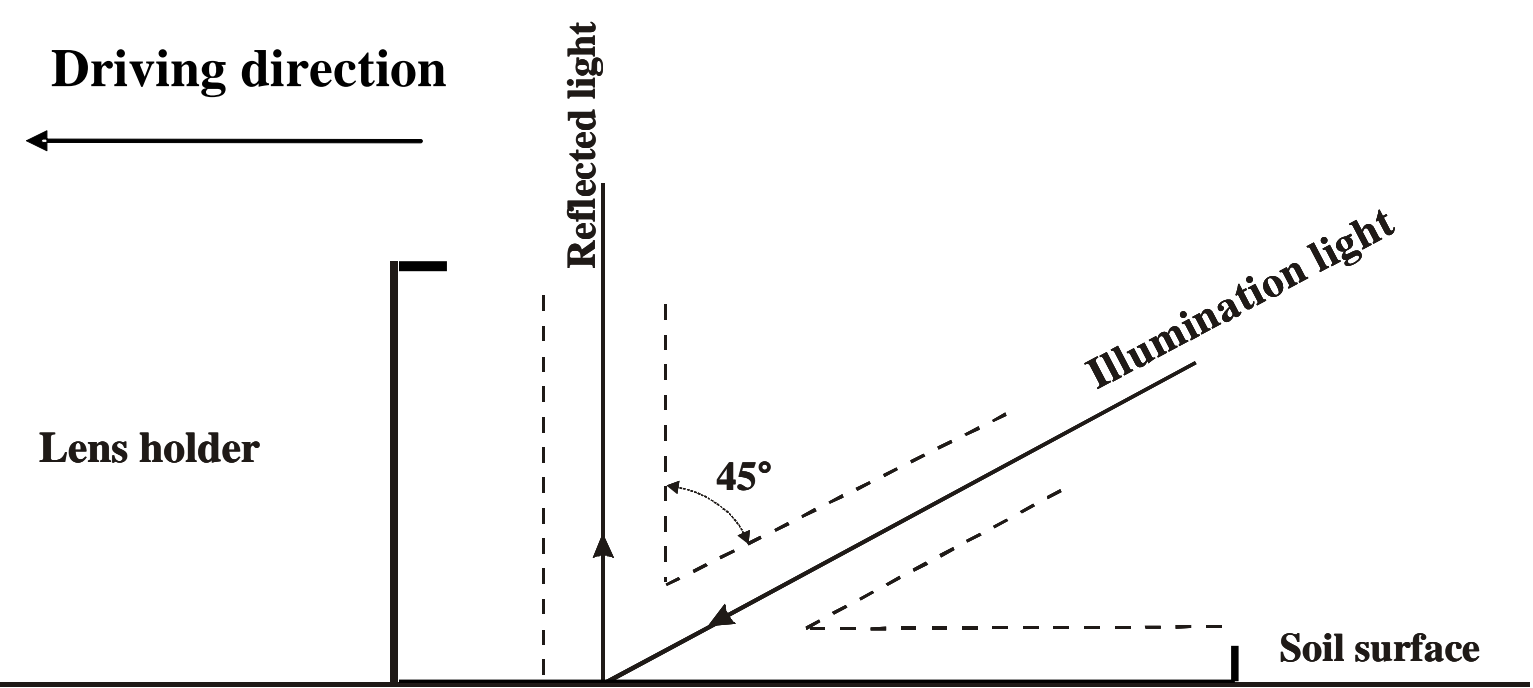

(a)

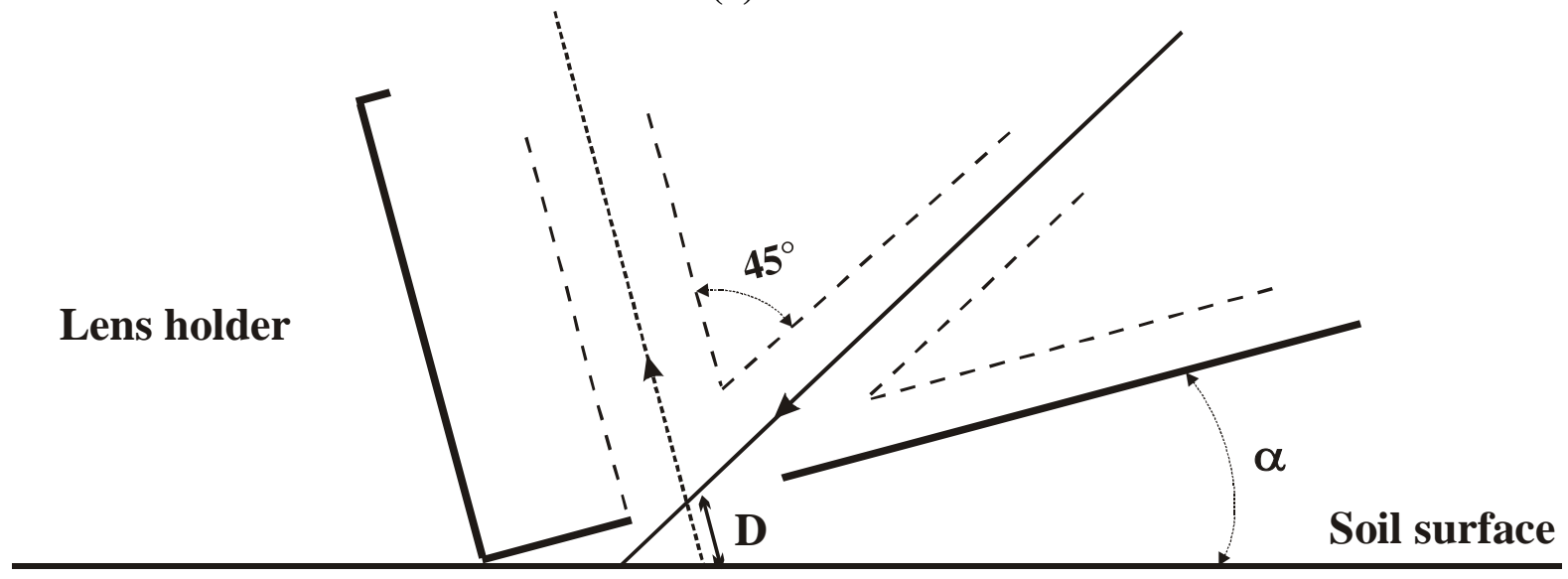

(b)

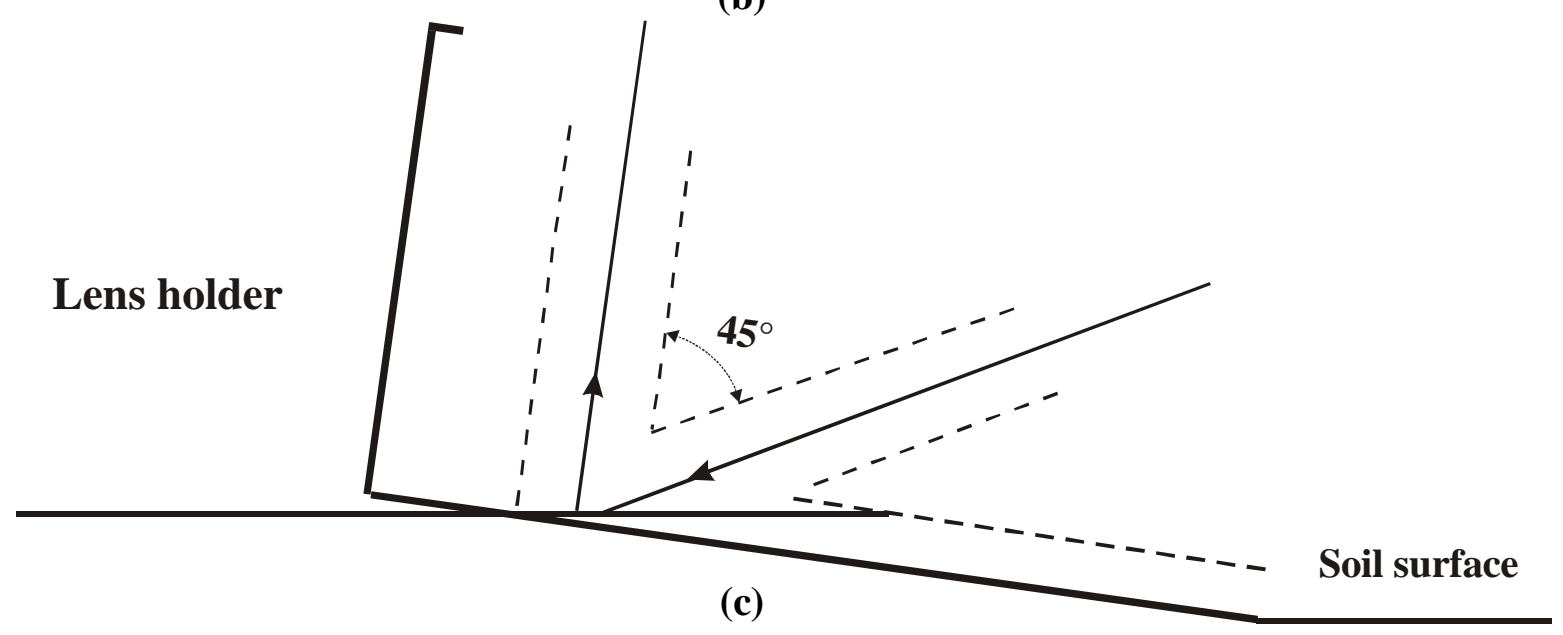

Fig. 2. Optical path throughout the optical probe for (a) tine at optimal position (b) tine inclined backward (c) tine inclined forward 
Soil and Tillage Research, Volume 103, Issue 1, April 2009, Pages 144-152

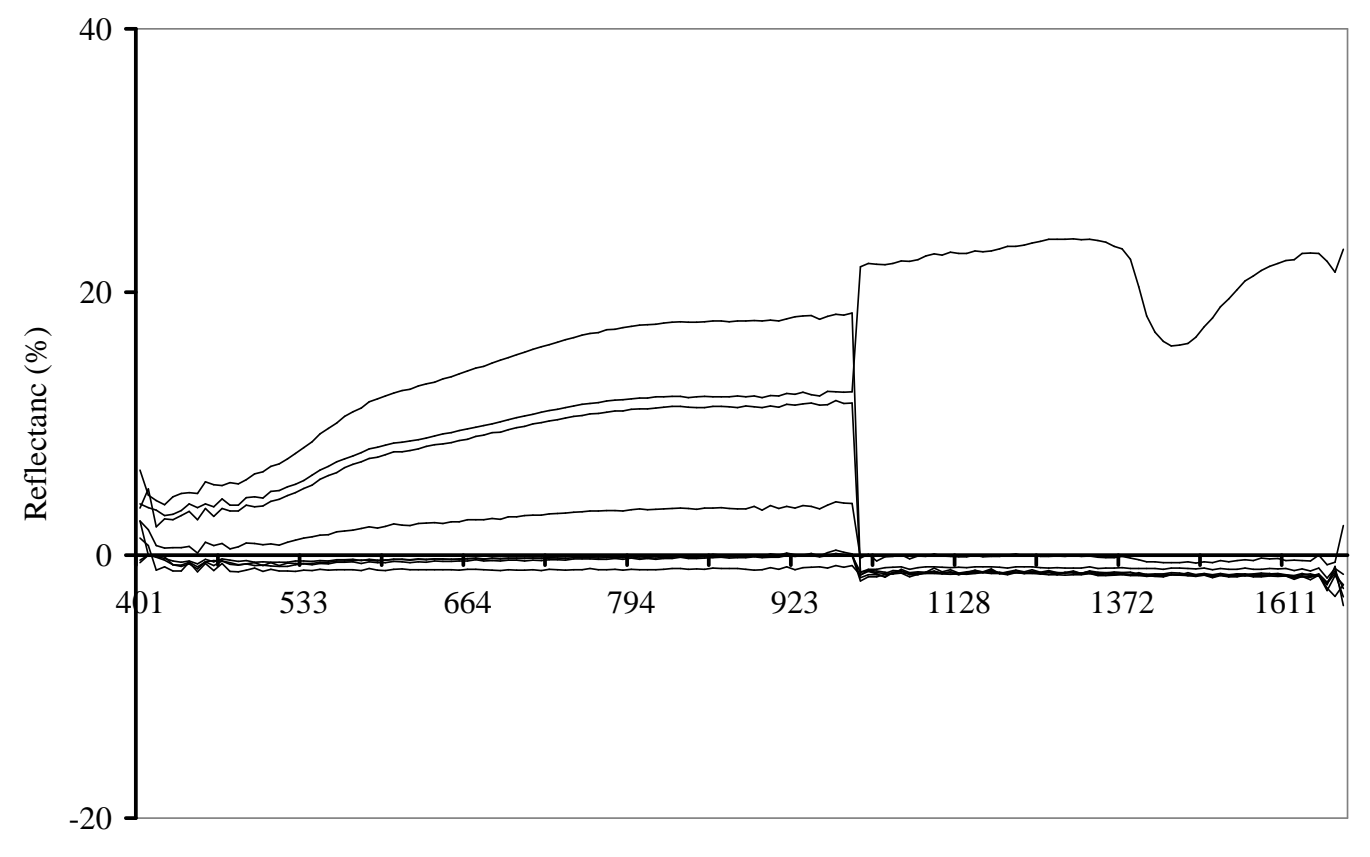

Wavelength (nm)

(a)

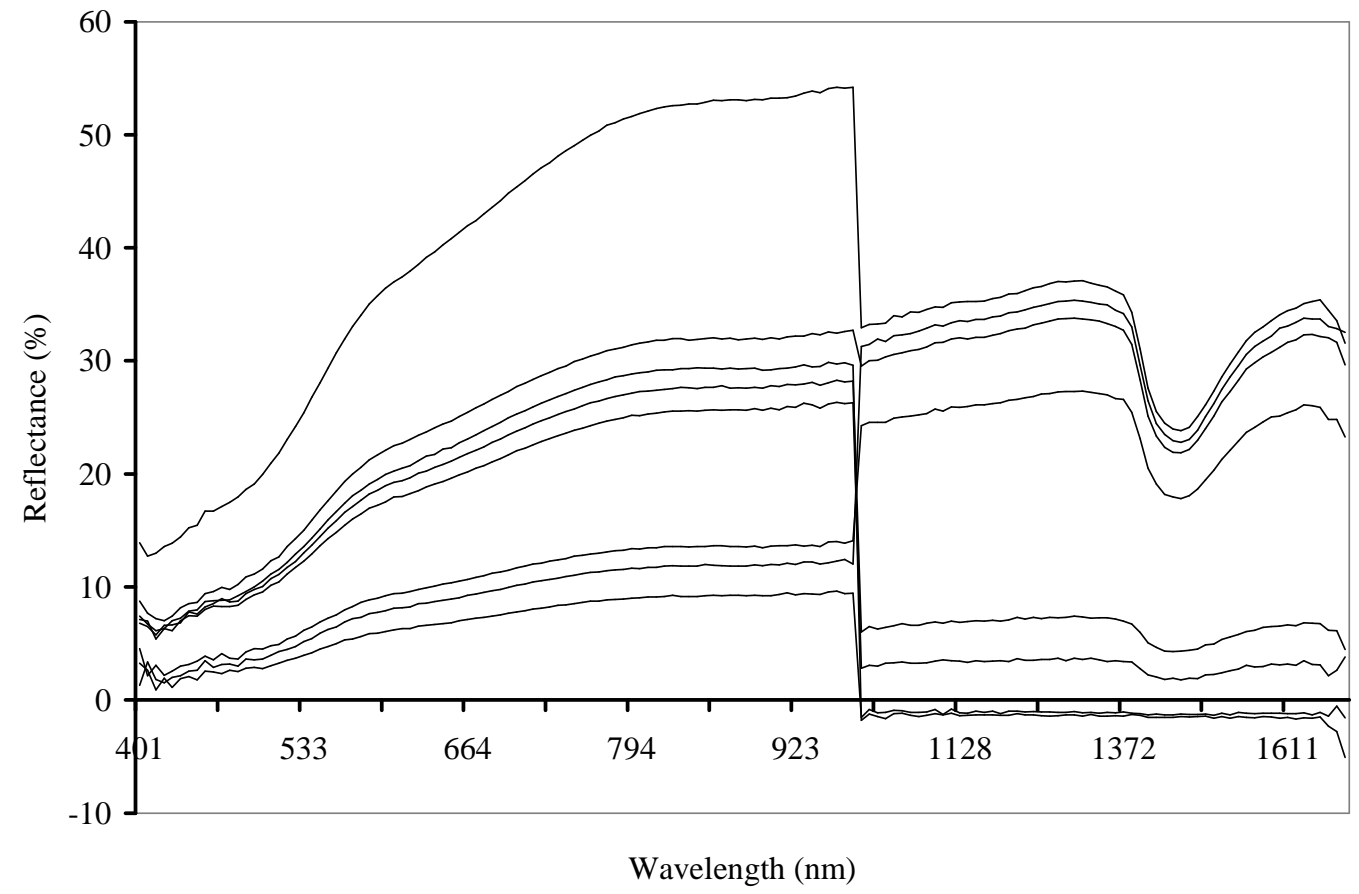

(b) 
Soil and Tillage Research, Volume 103, Issue 1, April 2009, Pages 144-152

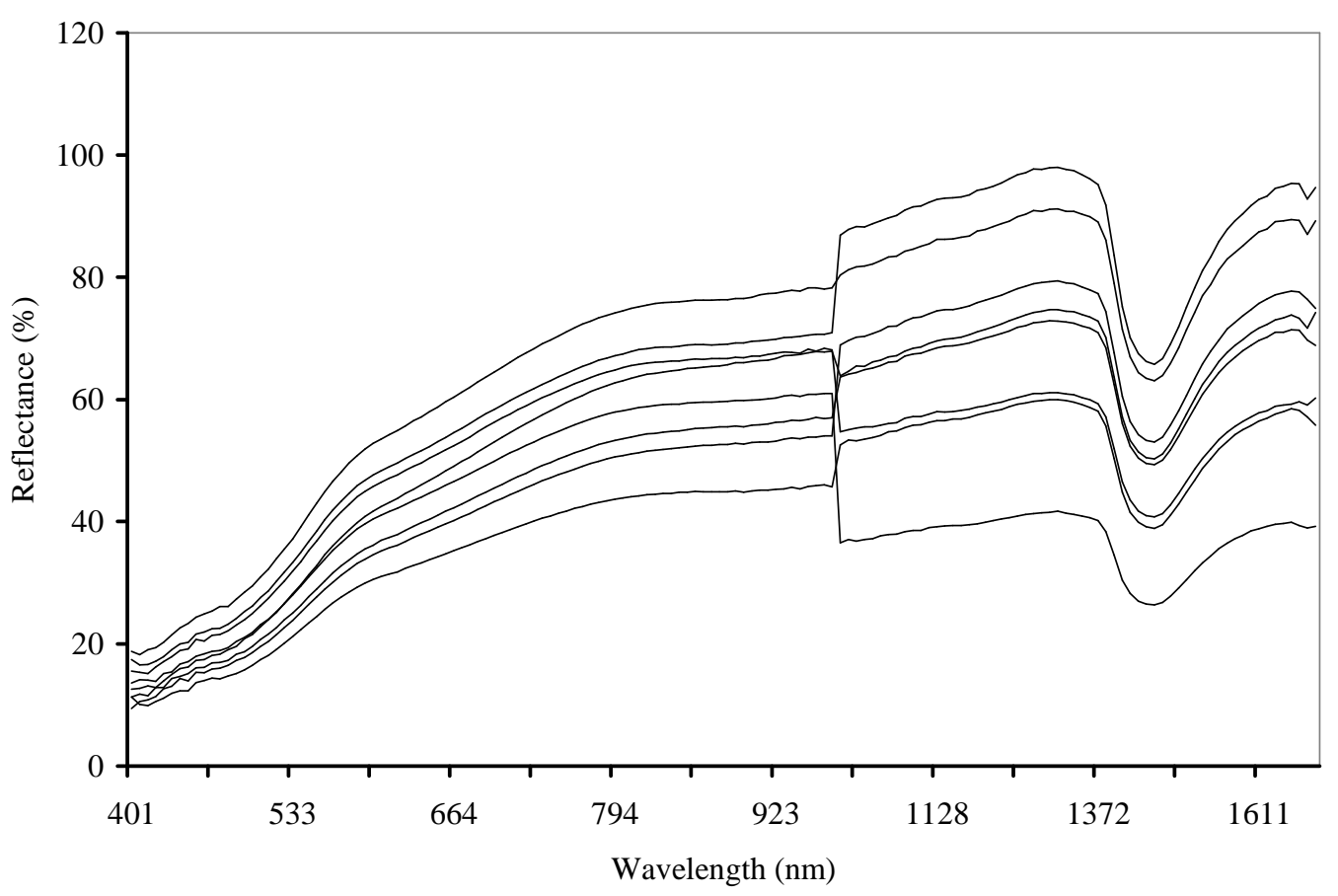

(c)

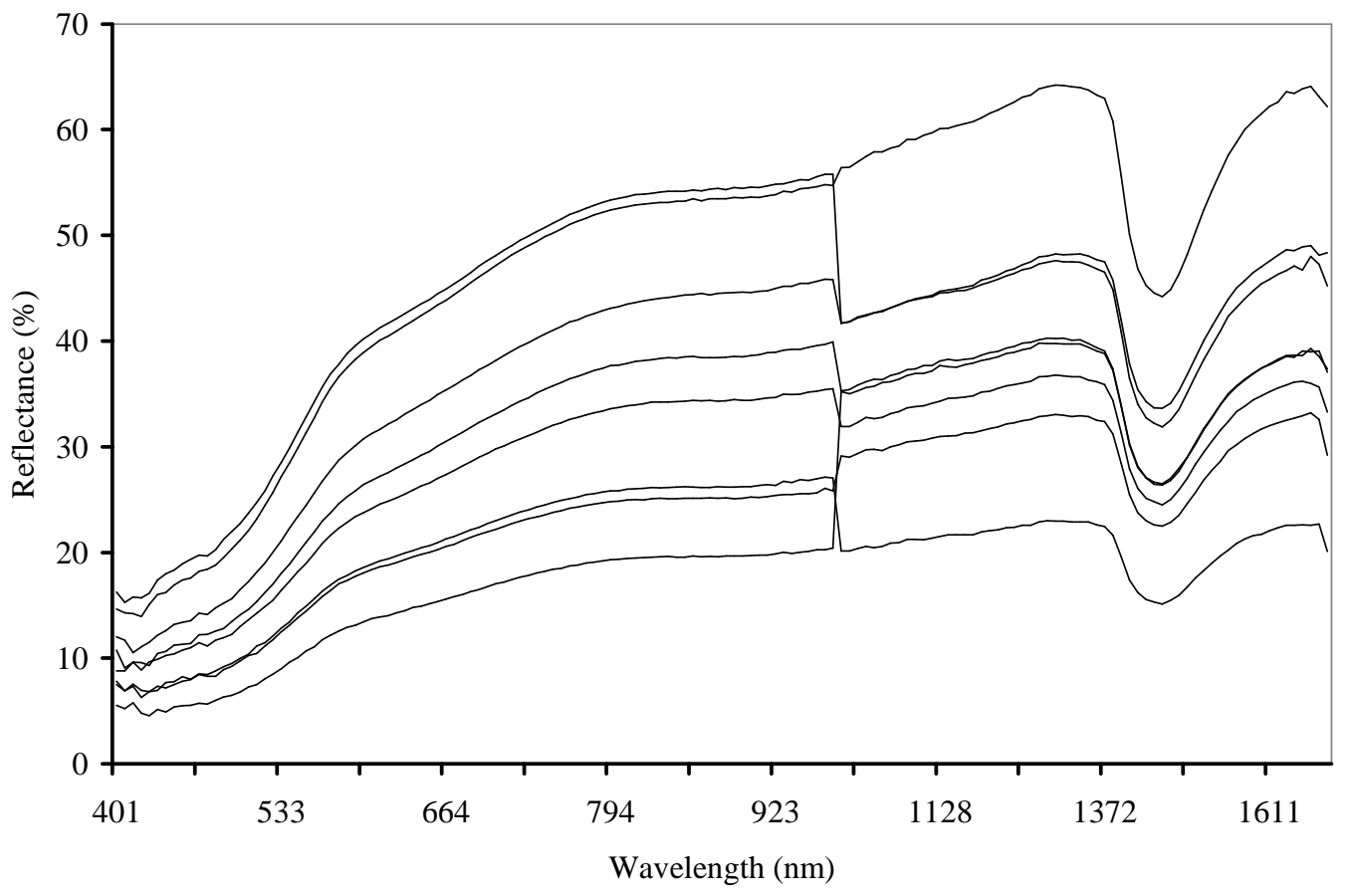

(d) 
Soil and Tillage Research, Volume 103, Issue 1, April 2009, Pages 144-152

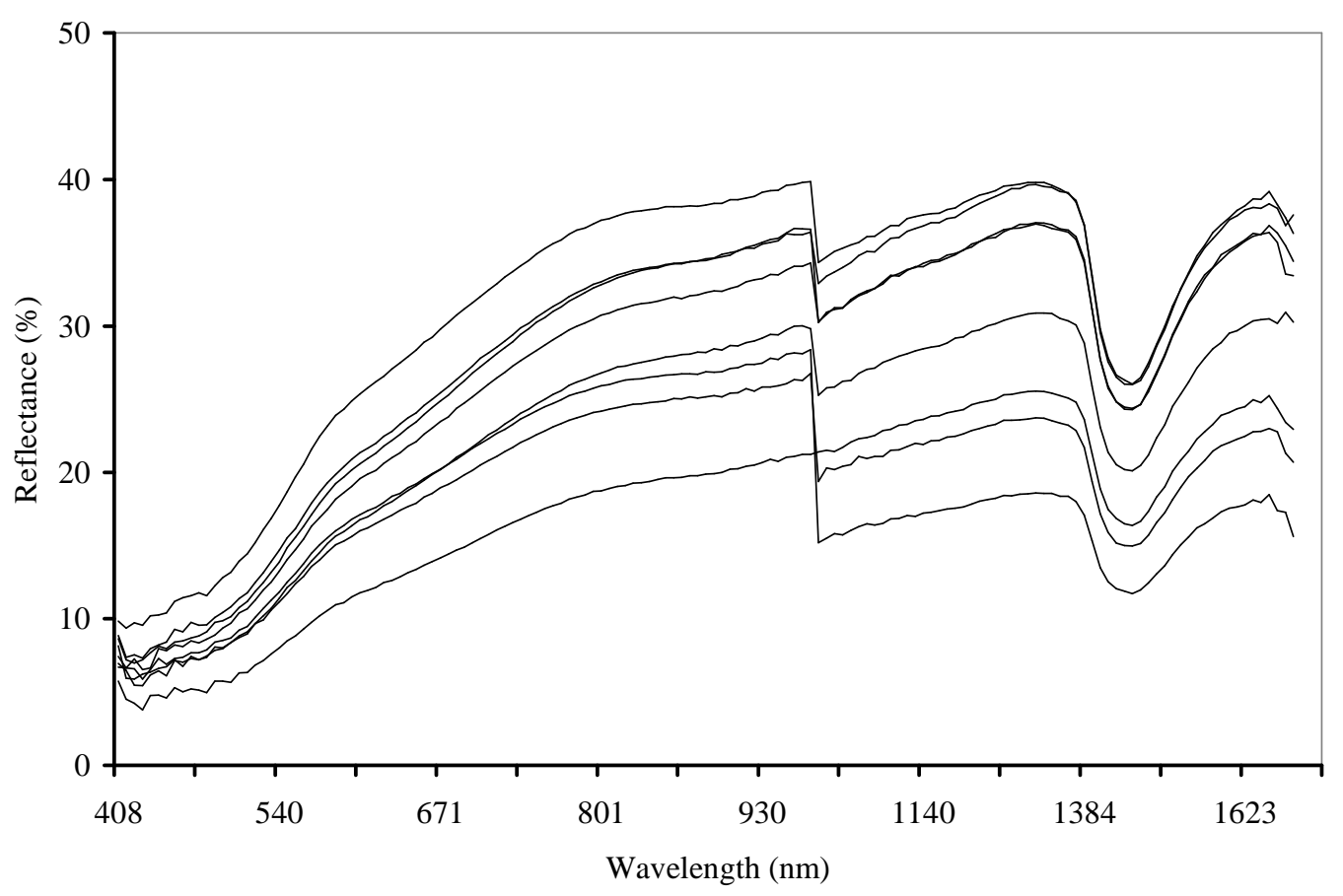

(e)

Fig.3. Recorded soil spectra at different probe inclination angles $(\alpha)$ resulted from different lengths of the tractor third-point link $(L) ;(a) \alpha=0.6^{\circ}$ at $L=545 \mathrm{~mm} ;(b) \alpha=$ $0.3^{\circ}$ at $L=550 \mathrm{~mm} ;(c) \alpha=0.0^{\circ}$ at $L=555 \mathrm{~mm} ;(d) \alpha=-0.2^{\circ}$ at $L=558 \mathrm{~mm} ;(e) \alpha=$ $0.6^{\circ}$ at $L=565 \mathrm{~mm}$ 


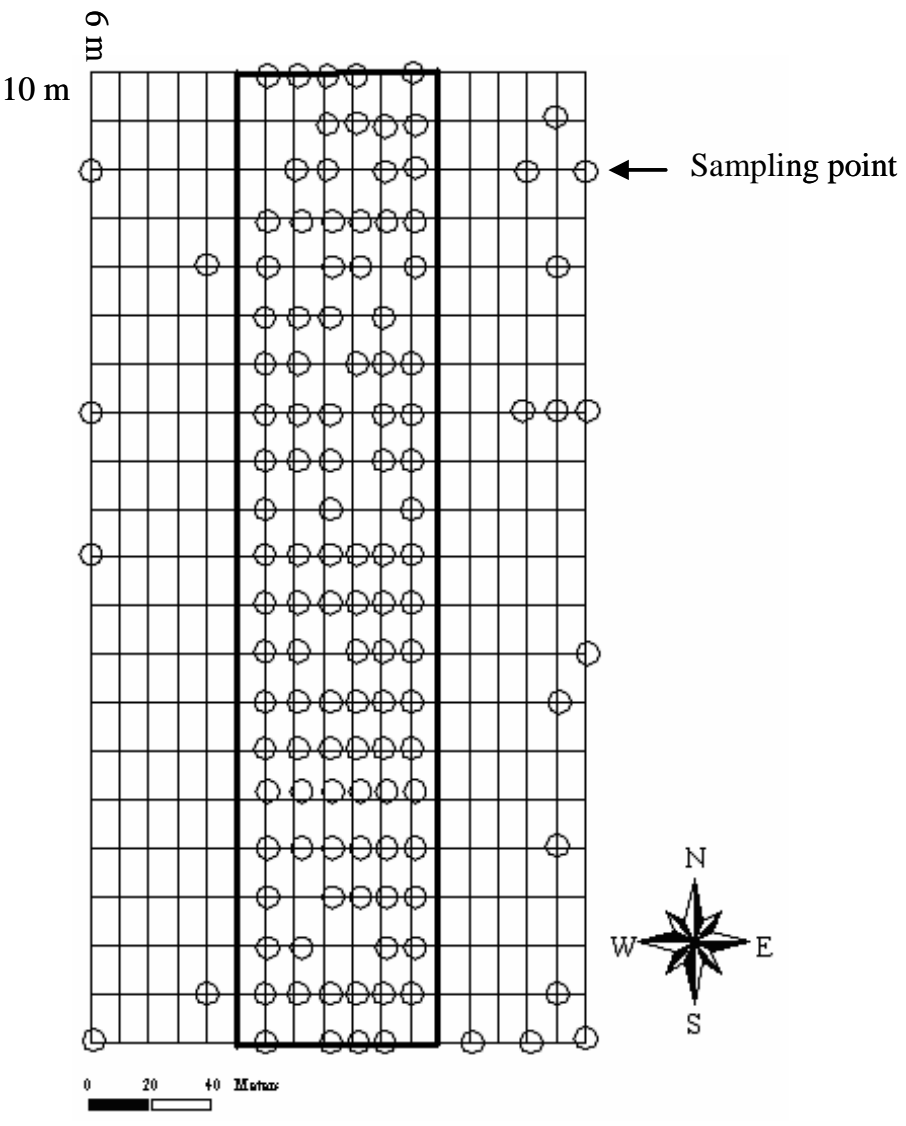

Fig. 4. Soil sampling locations in a grid of 6 by $10 \mathrm{~m}$ in a 100 by $200 \mathrm{~m}$ Lovenjoel field 
Soil and Tillage Research, Volume 103, Issue 1, April 2009, Pages 144-152

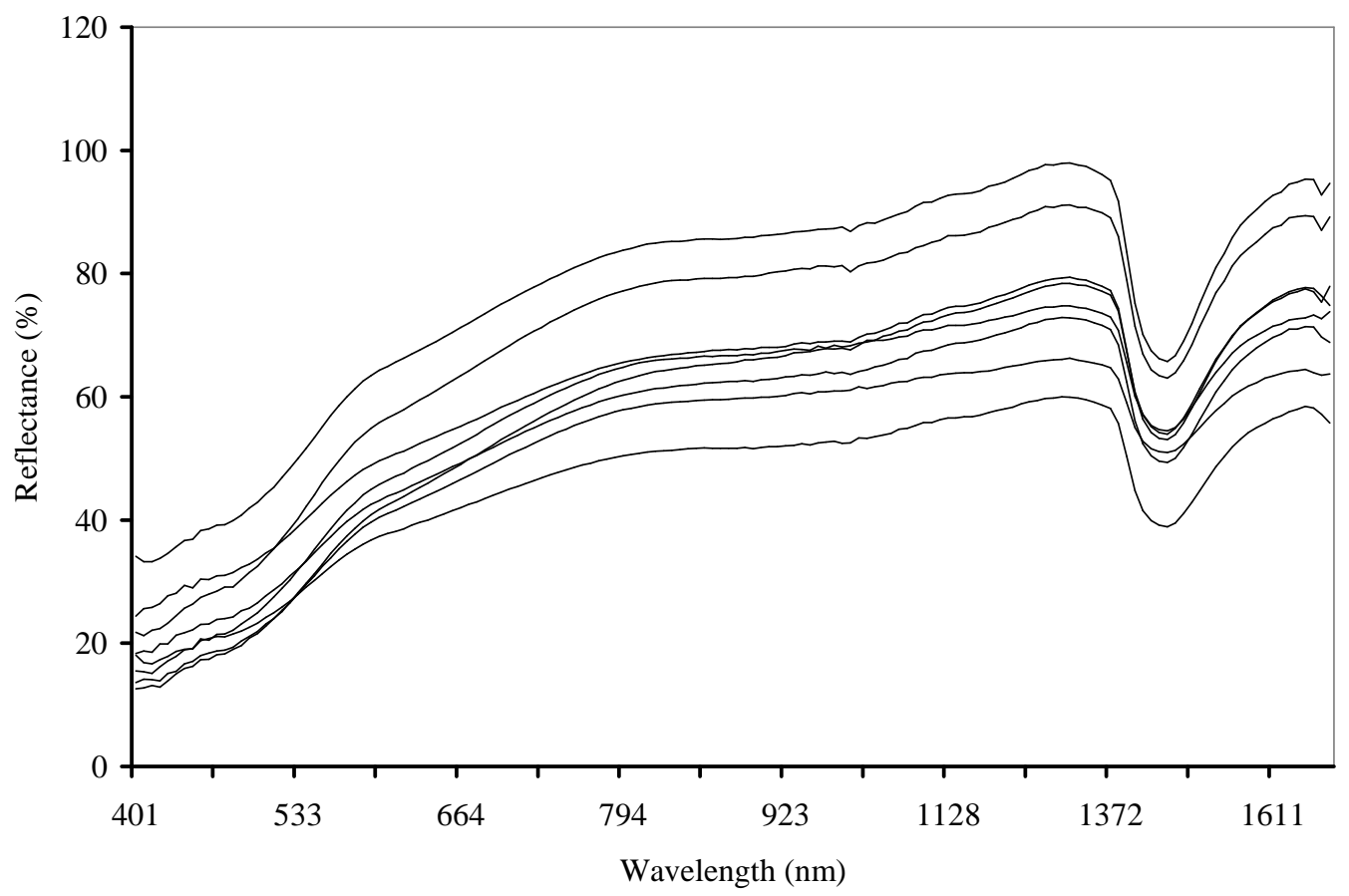

Fig. 5. Corrected spectra measured for line C in Heverlee field with $555 \mathrm{~mm}$ long third point link $(L)$ 


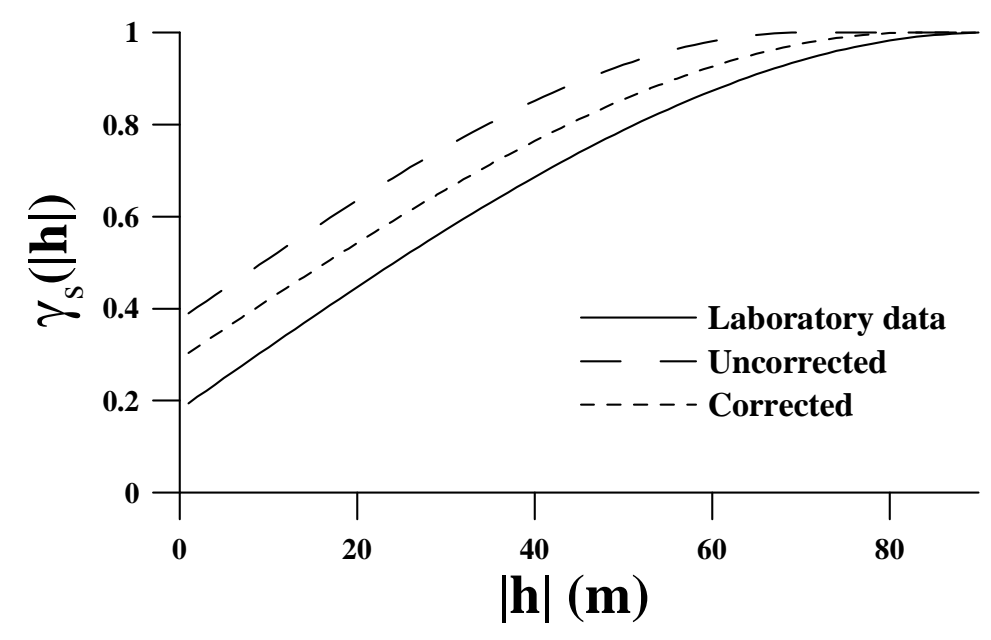

Fig. 6. Standardised variograms of plant available phosphorus in soil (P-avl) based on laboratory chemical analysis, uncorrected and corrected on-line measured soil spectra in Lovenjoel field 
Soil and Tillage Research, Volume 103, Issue 1, April 2009, Pages 144-152
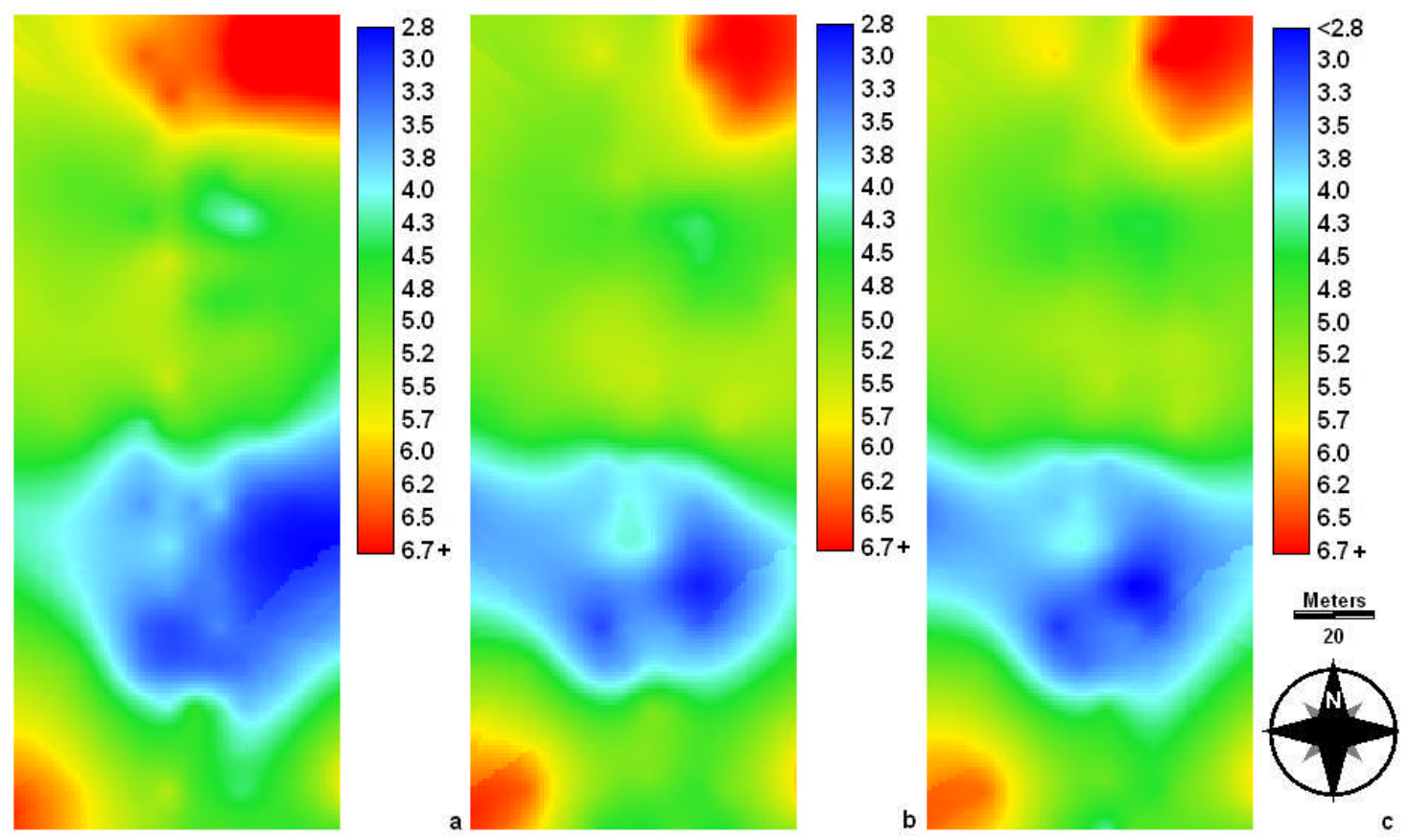

Fig. 7. A 1 by $1 \mathrm{~m}$ grid obtained by ordinary kriging of plant available phosphorus in soil (P-avl) based on: (a) laboratory chemical analysis, (b) uncorrected, and (c) corrected on-line measured soil spectra in Lovenjoel field 

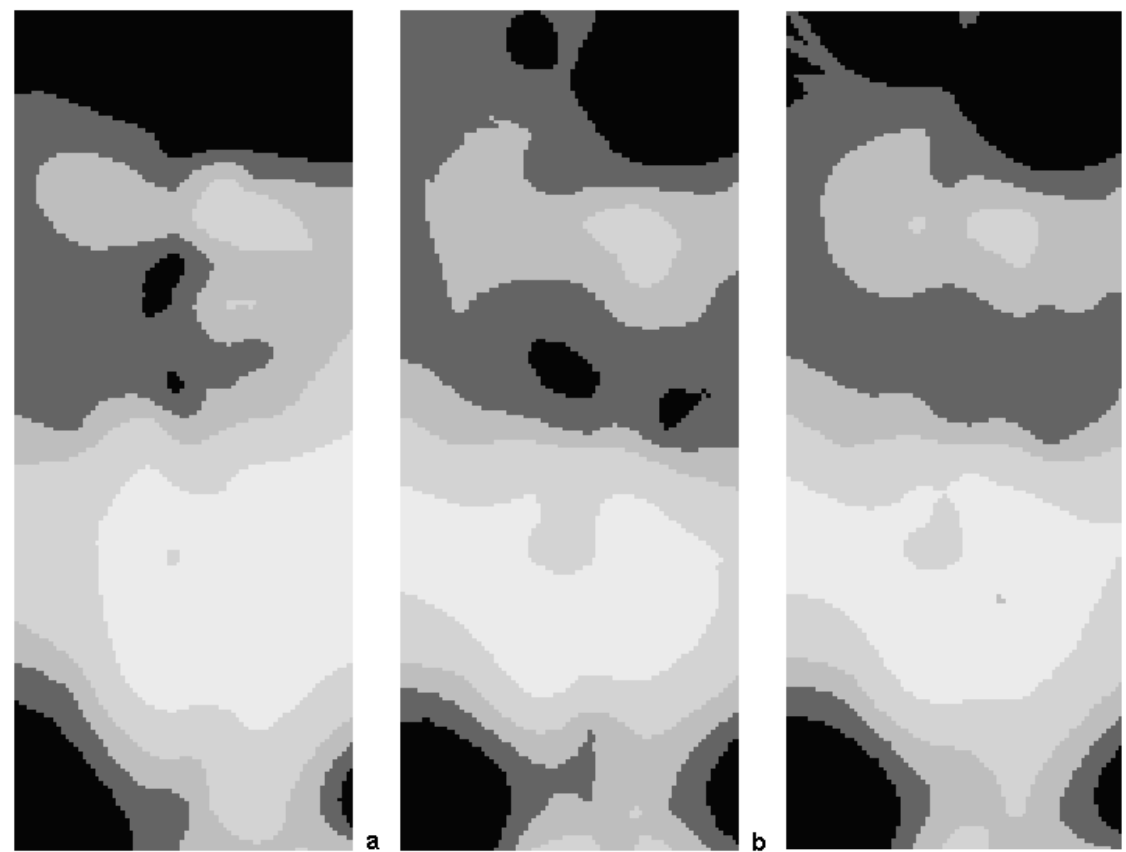

Fig. 8. Categorical maps of plant available phosphorus in soil (P-avl) based on (a) laboratory chemical analysis, (b) uncorrected, and (c) corrected on-line measured soil spectra in Lovenjoel field 